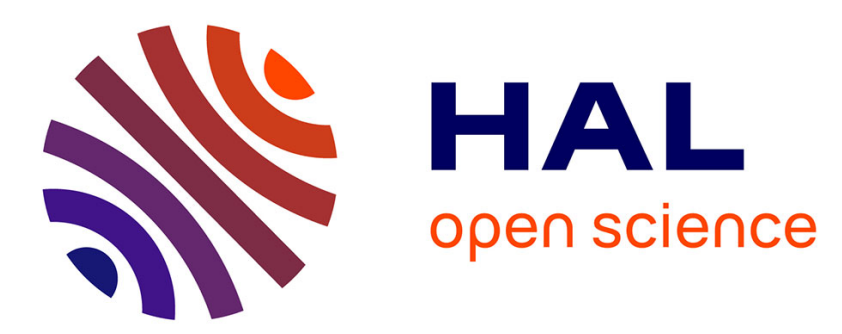

\title{
The challenge of assessing social cohesion in health impact assessment
}

Julie Romagon, Françoise Jabot

\section{To cite this version:}

Julie Romagon, Françoise Jabot. The challenge of assessing social cohesion in health impact assessment. Health Promotion International, 2021, 36 (3), pp.753-764. 10.1093/heapro/daaa067 . hal03122562

HAL Id: hal-03122562

\section{https://hal-univ-rennes1.archives-ouvertes.fr/hal-03122562}

Submitted on 5 Feb 2021

HAL is a multi-disciplinary open access archive for the deposit and dissemination of scientific research documents, whether they are published or not. The documents may come from teaching and research institutions in France or abroad, or from public or private research centers.
L'archive ouverte pluridisciplinaire HAL, est destinée au dépôt et à la diffusion de documents scientifiques de niveau recherche, publiés ou non, émanant des établissements d'enseignement et de recherche français ou étrangers, des laboratoires publics ou privés. 
The challenge of assessing social cohesion in Health impact assessment

Julie Romagon ${ }^{1}$, Francoise Jabot ${ }^{2}$

1 - Univ Rennes, EHESP, F-35000 Rennes, France.

2 - Univ Rennes, EHESP, CNRS, ARENES -UMR 6051, F-35000 Rennes, France. 


\title{
The challenge of assessing social cohesion in Health impact assessment
}

\begin{abstract}
Health impact assessment (HIA) is a method by which a policy, programme or project falling outside traditional health fields, may be judged as to its potential effects on the health of a population in order to mitigate negative impacts and strengthen the positive ones. Proposals are analysed from the perspective of all the determinants of health. In France, HIAs are mainly applied to urban development projects where social cohesion is a major issue. Although the HIA method is well structured as a step-by-step process, there are no guidelines for assessing social cohesion. This article opens with literature review to clarify the concept of social cohesion, and to understand how the built environment influences social cohesion and how social environment influence health. Drawing on this work, this paper presents an analytical framework to assess social cohesion, integrating both the spatial and physical dimensions of urban design and the perceptions of the neighbourhood characteristics. Following a brief overview of the key findings from applying this framework to HIA of an urban development project, the paper discusses its related strengths and weaknesses. The framework could be a useful tool for HIA as it embraces knowledge from both urban planning and social sciences. It also allows for an overall analysis of all the indicators without relying on a checklist. Nevertheless, it should be tested further to improve its validity.
\end{abstract}

\section{BACKGROUND}

Health impact assessment (HIA) is a method by which a policy, programme or project not mainly health related, may be judged as to its potential effects on the health of a population and the distribution of those effects within the population (World Health Organization, 1999). The purpose of HIA is to influence decision-making in favour of health by ensuring that health-related issues are considered and assessed in all policymaking in a democratic, equitable, sustainable and ethical manner. HIA is a structured process with the following steps: determining whether HIA is appropriate and feasible; setting out the scope and the parameters of HIA; analysing data and assessing health impacts; elaborating a set of recommendations to mitigate negative impacts and reinforce positive impacts; setting up a monitoring mechanism for recommendations; and evaluating the HIA process and its impact on health (Kemm, 2012). Health is considered as a complex and dynamic process due to the interaction between the different factors 
that can influence it such as physical environment, living conditions, social environment, perceptions, attitudes, lifestyle habits and behaviour (World Health Organization, 1986). In HIA, proposals are analysed from the perspective of all these determinants of health. One major step involves identifying how the various components of a given project relate to health through health determinants by tracing the pathways that connect project components, determinants and health. These theoretical assumptions are tested against the scientific evidence and contextual data. HIA's method has largely been developed over the last twenty years and it is generally applied to urban development projects (Dannenberg, 2016). These combine various interventions on the built environment (BE) such as housing developments, roads, public spaces, new facilities and infrastructure, some of which are associated with regulatory measures.

In France, interest in HIA is relatively recent and the approach has mainly been applied to urban development projects, many of which have been implemented in deprived areas with low-income households (Author, 2017). These areas give rise to specific policies and funding schemes, with social issues and inequalities being a major concern for policy makers. They turn to HIA capacity in the hope to gain insights on how projects may improve social cohesion and health through living conditions. Social factors shaping environments in which people live are crucial as they influence the resources available for individuals to satisfy their fundamental needs and adapt to their environment. HIA practitioners face two challenges when assessing social cohesion. First, although it may be straightforward to establish links between some project components, some health determinants and health outcomes (transport, air quality and respiratory diseases for instance), the links to the social determinants of health are less obvious. Mechanisms on how the BE influences the social environment and health are numerous and intertwined, and not always clearly identified (Mazumdar et al., 2017). Second, many different concepts underlap social cohesion and social capital, which means scientific evidence is 
difficult to use in an approach such as HIA. This is especially true as it doesn't always offer conclusive evidence.

Drawing on a literature review about the links between the built and social environments, we sought to achieve an analytical framework for use in HIA and designed to assess the impact of urban development projects on social cohesion as a determinant of health. The framework was derived from HIA implemented on urban projects in France.

\section{METHODS}

Our research approach is based on concept analysis (Delves-Yates et al., 2018; Mpanje et al., 2018) and includes the four stages set out below.

Stage 1. We conducted a literature review in order to: clarify the meaning of social cohesion, identify the surrogate terms (social capital, social support, social ties, etc.), disentangle the concepts associated and set out an operational definition, map out the current state of knowledge about how social environment influences health (operating mechanisms) and how the BE influences social determinants, especially social cohesion.

We performed a review of scientific and grey literature and started with literature reviews whether systematic or not. We conducted our search on five databases (Google Scholar, ScienceDirect, Springer Link, PubMed et la Banque de Données en Santé Publique) using the following keywords: Built Environment, Urban Design, Public Space, Urban Environment, Urban Planning, Green Areas, Green space, Park, Neighbourhood design I Social environment, Social capital, Social network, Social ties, Social support, Social participation, Social inclusion, Social mix, Community / Health. The literature reviews were supplemented with specific studies and reports to analyse more thoroughly some additional themes and concepts. Databases (Google Scholar, ScienceDirect and 


\begin{abstract}
PubMed) were also searched for HIA reports or articles focusing on social cohesion in urban projects as well as articles on the social impact assessment method. Research was limited to papers in English and French.
\end{abstract}

Stage 2. Drawing upon the literature, we identified the features of the BE which influence social cohesion and the mechanisms behind this influence in order to establish the full causal chain between the $\mathrm{BE}$ and health through social factors.

Stage 3. We carried out a HIA of a wasteland redevelopment project located between disadvantaged neighbourhoods and the city centre in Lille (France). This new district was intended to be appealing for all inhabitants, to improve the continuity between the different districts and the social link between the newcomers and the local residents. Equity regarding access to services and social cohesion were major concerns. We used the findings from the literature to identify urban design attributes that may have impact on social cohesion. We broke down each relevant component of the BE into several questions and variables for analysis and indicators to assess and then designed a first draft of the framework that we applied for this HIA. We found that the analysis could not be limited to the BE variables that questioned the relevance of only assessing urban design attributes without looking further into the characteristics of the population and people's perception. We decided to improve the framework by developing more precise and diverse variables and indicators for the human dimension and by looking further into variables of SCo itself.

Stage 4. Faced with a second HIA of an urban development project in Strasbourg with similar issues of urban continuity and social mix, we applied this new framework to assess its usefulness in the evaluation of social cohesion.

\title{
RESULTS
}




\section{Literature findings}

\section{What is social cohesion?}

Over the past 20 years, research on social capital has increased. A number of articles have dealt with various concepts such as social relations, social network, social inclusion, social support, social capital, social cohesion. Different authors use different and overlapping definitions, particularly social capital (SC) and social cohesion (SCo) (Moore and Kawachi, 2017).

A first group of concepts concerns the individual and the connectedness between individuals. Social relations or interpersonal ties are connections with people, either weak or strong, such as family members, friends, acquaintances, coworkers. Several ties with different individuals are usually described as a social network. Social exclusion is presented as "a multidimensional process of progressive social rupture, detaching groups and individuals from social relations and institutions and preventing them from full participation in the normal, normatively prescribed activities of the society in which they live" (Silver, 2007). Social inclusion is mostly defined as the opposite of exclusion.

A second group of concepts underlines the idea the social environment provides individuals with the resources to manage their lives and improve their health. Literature about social capital is abundant and draws on the work of Bourdieu, Coleman and Putnam (Carpiano, 2006). Social capita/ refers to people's resources and potential for managing their lives. It comes about through networks and social relations and social processes such as trust, reciprocity and collective engagement (Carpiano, 2006). For some authors, it happens on an individual level whereas others emphasise the community level. SC is seen as the capacity to draw on resources from social networks (Portes, 1998) or to access other resources (Bourdieu, 1980). These resources are elements of the social structures (trust, reciprocity norms, mutual help) for individuals and facilitating collective 
actions (Carpiano, 2006; Goldberg et al., 2002). Thus, social support is mentioned as a form of resource given by social networks and ties -people to whom an individual can turn when in need (Beauregard and Dumont, 1996). Three types of SC have been defined based on the function and nature of the ties created between individuals (Moore and Kawachi, 2017). Bonding SC brings together people who share similar values, interests and experiences. It is useful on a daily basis and strengthens their identities within homogenous groups. In contrast, bridging SC refers to ties between heterogeneous groups where members are of different generations, cultures, religions or status. This generates trust, better understanding and mutual tolerance, allowing people to open up and change perspective. Linking SC establishes connections between people and service providers, institutions and sources of power beyond the neighbourhood.

Social cohesion (SCo) differs from SC in that it acts as a mediator and "serves as the basis from which SC can be formed" due to trust, familiarity, values, and network ties shared among people (Carpiano, 2006). It is the expression of ties and solidarity between groups in a society and the absence of latent conflicts, including a sense of belonging to a place or community (Kearns and Forrest, 2000). It has been defined as "the glue that holds societies together and without which there can be no economic growth or human wellbeing"(Grootaert and Van Bastelaer, 2001). It is used in the field of policy making, particularly for European policies as a way to improve well-being and political stability (Klein, 2013). In France, the term "social cohesion" is being widely used in politics, especially in local urban policy making. It refers to both an expected outcome and the principle behind urban policy. Policy makers approach SCo through social and cultural homogeneity, solidarity, trust, and sense of belonging. (Guibet-Lafaye and Kieffer, 2012). Social cohesion has been included in strategic policy documents in France - and more broadly in Europe - and is more meaningful for decision makers (than social capital) for whom it is the synonym for "vivre ensemble", namely, the ability of a group to live together 
in a geographical area. Therefore, while social capital is a prevalent term used across many disciplines to conceptualise the social environment, we used social cohesion as our main concept. The latter concerns a more collective level, even if individual and institutional levels have to be considered (Fonseca et al., 2019), and therefore lends itself better to urban planning and policy making. In conclusion, social cohesion can be seen as the product of some of the previous concepts defined here (social support, social network) taken on a bigger scale (a city, a town, a neighbourhood), while the other concepts are mostly looked at on a smaller scale (an individual's ties within a specific neighbourhood). It is important to understand these different scales when assessing social cohesion through the lens of the BE. With regard to HIAs, the question addresses social cohesion as understood by decision makers, and in relation to urban policy in France.

\section{Social environment and Health}

Several studies have shown a link between an individual's social environment and health (Moore and Kawachi, 2017). Associations have been found between SC and health (Ehsan et al., 2019), and between levels of SC and mortality rates in different countries across the world (Meijer et al., 2012; Murayama et al., 2012; Walsh et al., 2015). Moreover, people with high levels of SC declare their health to be better than others. Other associations were found between social participation and mortality (Jenkinson et al., 2013; Nyqvist et al., 2014), between SC and lung cancer (Hamano et al., 2019), SC and non communicable diseases (Hu et al., 2014) especially for cardiovascular diseases, diabetes and cancer. A good level of SC and social support could help with the recovery (Ewing and Kreutzer, 2006 ), while socially isolated people were more at risk of dying after a pathology than people with a lot of ties (Chaix et al., 2008). Conversely, in several studies, social isolation is linked to bad health, notably stress and depression (d'Hombres 
et al., 2010; McPherson et al., 2013). Some studies have also found links between SC, SCo and psychological well-being (Ewing and Kreutzer, 2006; Hassen and Kaufman, 2016). A systematic review found that high levels of social capital could prevent the development of common mental health problems (Ehsan and Silva, 2015). Participation in community activities can contribute to reducing stress (Leslie and Cerin, 2008), behaviour and mental problems among children (McPherson et al., 2013).

Some authors postulated that the links between social determinants and health are explained by three key mechanisms, which act at the individual and collective levels. First, social support contributes to improving self-confidence and access to health-care services (Kawachi et al., 1999; Stansfeld, 1999; Walsh et al., 2015). By facilitating access to information and health resources, social support could play a protective role against life events that could cause harm to health (d'Hombres et al., 2010; Ehsan and Silva, 2015). Second, informal social control leads to the adoption of norms that are in favour of healthy behaviour (physical activity) or limiting risky behaviour (alcohol and drug use) (Berkman et al., 2000; Kawachi et al., 1999; Yuma-Guerrero et al., 2017). The third mechanism is collective efficiency, namely the willingness to intervene in the name of the common good through social cohesion established between neighbours (Cohen et al., 2008). Thus, SC can contribute to creating a healthy neighbourhood with collective involvement (Maass et al., 2016) or collective action by some neighbourhoods towards local authorities (Yuma-Guerrero et al., 2017).

A recent analysis of systematic reviews shows that the relationship between SC and health is generally positive with a good level of evidence. It also highlights limitations and grey areas to the extent that reviews often provide only certain pieces of the puzzle, do not always conceptualize SC in the same way, or use different measurement methods and indicators (Ehsan et al, 2019). Authors also note that few studies are able to untangle 
the web between SC and health and that the results can be contradictory, as they vary according to context or population type.

Public health interventions targeting SC include a variety of activities operating at different levels and assigning different roles to SC, such as target, mediator or segmenting variable for identifying potential beneficiaries (Moore and Kawachi, 2017). In line with this classification, SC is a mediating factor between interventions on the BE and health outcomes but also an insight for anticipate negative impacts for specific groups (Villalonga-Olives et al., 2018).

\section{Social cohesion through the lens of the built environment}

The urban BE is defined as "the human-made space in which people live, work and recreate on a day-to-day basis. It includes the buildings and spaces we create or modify" within the urban settings (Roof and Oleru, 2008). The main components of the BE are public spaces such as those used for traffic and travel, roads, sidewalks, green spaces, parks, squares as well as private spaces such as businesses, facilities, houses and types of housing (Renalds et al., 2010).

The scientific literature pinpoints the effect of the BE on the social environment which in turn influences people's relationships towards one another, their ties, and network, which can lead to effects on health and healthy behaviours (Mazumdar et al., 2017). The BE influences social cohesion in numerous and intertwined ways. These refer to structural changes in space (urban planning), related policies (housing, social, educational, economic) and how citizens may take ownership of places through (their) "psychosocial orientation and attachment factors" (Baldwin, 2015).

\section{Urban design}


Urban planning, and more specifically public spaces, can affect social cohesion to the extent that it creates places where people can mingle and form groups. Such places can be conducive to common activities, and thus increase the potential for individuals and groups to meet (Baum et al., 2009). Therefore, the characteristics of the BE (design, density, connectivity of public spaces, functional diversity, urban furniture) may or may not encourage contact between individuals based on planned or unplanned interactions (Renalds et al., 2010). These interactions can be the beginnings of stronger and more supportive forms of social relationships and the structuring of social networks.

Several places have been identified in the literature as places for informal encounters: public spaces, particularly green spaces (Boessen et al., 2017; Mazumdar et al., 2017), equipped with benches for the elderly and sedentary women living alone (Ottoni et al., 2016), sidewalks and pedestrian areas, and porches in front of houses (Cabrera and Najarian, 2015). On the other hand, the lack of identifiable places would be an obstacle to the formation of a social network (Hanna et al., 2009). Housing design can also promote the formation of social networks. For example, when the entrances to houses or buildings face each other, are adjacent or connected to a pedestrian walkway or meeting places, the probability of social interactions is higher (Lavin et al., 2006). However, lack of privacy and overcrowding are variables associated with stress (Wood et al., 2008). Similarly, neighbourhoods that are conducive to walking and have diverse functions (shops, cultural and leisure activities, services, transport) would promote the potential for meeting, strengthen the sense of security and encourage political and social engagement of residents in the community (Foster et al., 2010; Hassen and Kaufman, 2016). These neighbourhoods are suitable for walking because of several attributes: street connectivity, number of intersections, sidewalk quality, pedestrian crossings, traffic lights and street furniture (Hassen and Kaufman, 2016). According to some studies, people living in walkable neighbourhoods have better levels of social capital than those living in areas 
where they depend on the car (Renalds et al., 2010). The urban density of a neighbourhood or city has, according to traffic intensity and population density, contrasting effects on social cohesion. They may encourage or discourage individuals from spending time outdoors (Boessen et al., 2017; Wood et al., 2008).

\section{Social diversity}

Implementing social diversity in a neighbourhood does not necessarily imply that the different groups will actively and positively interact, as it has been shown in the Netherlands and in the UK (Kempen and Bolt, 2009). Sometimes, it can lead to conflictual situations, alter trust between groups, disrupt solidarity networks and deprive the most vulnerable people of their social support (Bacqué et al., 2011; Lelévrier, 2013; Melis et al., 2013; (Villalonga-Olives and Kawachi, 2017)). Being socially and culturally close to one's neighbours can help as they can provide support in similar situations, maintain cultural traditions, language, heritage and they provide an overall feeling of safety (Phillips, 2006; Tomlins et al., 2002). Some aspect of social mix can work: when the income difference between groups is not too wide (Kempen and Bolt, 2009), or when social diversity is very low, such as within buildings (Melis et al., 2013). However, too much diversity at a small scale has also been associated with tensions between neighbours (Goodchild and Cole, 2001). The effects of cohabitation in the same area depend on the scale at which such cohabitation is achieved and the gap between groups. Thus, the social mix strategy itself is not enough to create social cohesion. It depends on other policies associated with residents and designed to engage them altogether (Mugnano and Palvarini, 2013).

\section{Perception of neighbourhood}


Neighbourhood characteristics (population density, traffic levels and safety, aesthetics, presence of vegetation, functional mix) influence people's perception of their surroundings in terms of sense of security (Leslie and Cerin, 2008). While the presence of a large number of individuals in a neighbourhood is supposed to make it more secure (Hillier, 2004), studies have shown that the arrival of new residents can create unwanted person to person contact with current residents which may lead to a decline in the number of residents using public spaces and therefore interact (Foster et al., 2010). Negative perceptions of the neighbourhood can prevent some individuals from participating in social activities to avoid certain places considered unsafe (Liska et al., 1988), resulting in a barrier to relationship formation and reduced social participation. In addition, other attributes such as urban lighting, clean streets, amenities, maintenance, increase satisfaction with home, may also facilitate social interactions and a sense of well-being (Wood et al., 2006).

The literature on the BE and social cohesion identifies mechanisms that may explain how the BE's features, such as public spaces and walkability, influences social interactions and social cohesion. These findings suggest that spatial, physical, and human factors must all be considered, as well as how they interact with one another. From these findings, an analytical framework was designed for HIA.

Figure 1. Pathways from built environment to health

\section{A FRAMEWORK FOR THE ASSESSMENT OF SOCIAL COHESION IN HIA}


The literature review allowed us to define social cohesion for the purposes of commissioning HIAs, to identify attributes of the BE that could influence social cohesion, and to understand the underlying mechanisms.

\section{Presentation of the analytical framework}

Following the literature review, we consider social cohesion as a construct that can be assessed using several criteria: shared interests and values, tolerance and acceptance of others, sense of common identity, sense of belonging to a territory. It is influenced by the degree of social distance between group members and the presence of social intermediaries.

To analyse urban projects, we considered two perspectives. The first refers to the spatial and physical dimensions of urban planning and the second to the human dimension. The latter relates to the way in which people, considering the geographical and social context, appropriate and invest urban space. We therefore built a framework that comprises criteria linked to each dimension, with specific questions and indicators to assess one by one and in a systemic way. The aim is to understand how each urban development project contributes to social cohesion as a whole (table 1).

Spatial dimension (or urban design)

Spatial dimension is analysed through four criteria: three related to public spaces (availability, accessibility and walkability, quality), and one related to functional diversity. Relevant indicators are sometimes available (e.g.: distance between spaces) while others have to be found by the HIA team (e.g.: quality of spaces).

\section{Human dimension}

This dimension is analysed through two main criteria. Social diversity is both influenced by urban design and social policies such as housing and education. Citizens' perceptions 
are studied through perceptions of the neighbourhood (safety, aesthetics, attractiveness, peacefulness, friendliness), attachment to the neighbourhood and sense of belonging.

Table 1. Social cohesion framework

\section{Application to the Port du Rhin urban redevelopment project HIA in Strasbourg}

The Port du Rhin urban redevelopment project (PdR-URP) is part of a larger project that has been underway for more than ten years. The PdR district is located in an industrial area on the outskirts of the city, along the river forming the border with Germany. It suffers from several disadvantages: isolation, poor housing, amenities, insufficient supply of shops and services. The inhabitants' state of health is poorer than the city average due to the deterioration of the living environment, air pollution in particular, social and economic insecurity as well as limited healthcare facilities.

Several interventions were planned: construction of more than 2000 housing units on the outskirts of the district and high standing housing along the river, redevelopment of public spaces and roads, a new tram line, establishment of private health facilities and local amenities (outlets, public services, bank, cultural centre). The project aimed not only to rehabilitate this neighbourhood but also to connect deprived areas to the city centre and to encourage social diversity by improving the area's appeal. Thus, when new people come to the district, whether to live or not, the population becomes more diverse with different backgrounds and socioeconomic status. Therefore, social cohesion was the main concern for decision makers.

To implement the HIA, we followed the step-by-step process according the international standards (Green et al., 2019) and we used a participative approach by which citizens were included in the steering committee and workshops. To collect data, we did the 
following: a) document and data analysis with urban planners, technical officers (to better understand the project); b) walks and field observations (to identify spaces and barriers for meeting); c) workshops with stakeholders and school-aged children, interviews, videos with young people, street interviews with the current residents (to identify perceptions). To analyse the parameters, we profiled the area and its population, we rated walkability and we conducted a qualitative analysis of the interviews.

\section{Findings}

The HIA stressed the improved living environment and also how the make-up of the resident population evolved according to the multiple changes (real estate, arrival of occasional people, workers, patients...) with potential impact in opposite directions.

The transformations, whether in terms of the development of public spaces or the provision of new services, are likely to create opportunities for encounters. This is particularly because they make the district more attractive and more accessible to all types of public given that currently the use of spaces is segmented between different social groups. However, by creating places of sociability and increasing population density with new activities, it can strengthen the sense of security in public spaces and increase the potential for social relations. Conversely, it can create conflict situations as this new population could be perceived as intrusive, which in turn could encourage people already settled to become withdrawn. Furthermore, the projected future residential distribution reveals varying degrees of diversity according to scale and a social specialisation of spaces between buildings to the east and west of the perimeter. It shows streets that could constitute a physical or symbolic barrier between different residential forms.

The renovation operations and the construction of new housing inspire contrasting feelings among the current inhabitants. They have felt dispossessed of their 
neighbourhood, particularly so after it was renamed and since some aedicules have been removed and wealthier newcomers have taken up residence. Renovation generates paradoxical effects with a risk of gentrification. These effects include, for the short, medium and long term, enhanced real estate through greater appeal, and better shops and businesses. However, these positive effects can lead in the longer term to population displacement. (Melis et al., 2013). The challenge is to ensure cohabitation between residents and newcomers who have different socioeconomic status. It will depend on the scale at which it is organised and the gap between these groups.

If the project is to be successful in terms of social cohesion, it must overcome several challenges: organising diversity at different scales compatible with the standards of the groups involved; reducing physical or symbolic barriers in order to guarantee access and appropriation of all spaces by all categories of population; organising the development of the district based on the local community fabric and with the involvement of the inhabitants in order to ensure the coexistence of different living practices.

\section{DISCUSSION}

The analytical framework offers some strengths and weaknesses.

\section{Three levels of weakness}

The three levels of weakness refer to the concept of SCo and its operationalization in HIA. The first is that SCo is a fuzzy concept for different reasons: it is used as a synonym of SC; it is an umbrella term for a number of related concepts; it is both a concept and a policy goal; and there is a discrepancy between policy makers who think social diversity means social cohesion, and researchers who think it is more complex. In the scientific literature, there are sometimes different definitions for a same concept, and close definitions for 
different terms. We tried to differentiate these concepts to grasp the complexity in which social environment is influenced by BE and by different mechanisms. We also need to understand expectations from the political perspective: what do policy makers mean when they want us to investigate social cohesion? Do we properly understand their perspectives and the definition in the literature?

The second level is related to conclusive evidence. Further studies need to be conducted to substantiate the links between the BE and SCo. Not only does evidence remain weak, with studies generally based on qualitative data, but also the causal link could be reversed due to multiple factors and interactions between the individual, his or her membership group(s) and the broader environment. Strong ties can feed sectarian and exclusive interests fueling the risk of opposition between groups, generations or cultures. Conversely, weak ties would allow less homogeneous groups to get along, without sharing the same ideals; they would help information to flow and establish bridges between communities; they would be conducive to stable urban life and open neighbourhoods (Cabrera and Najarian 2015; Crawford 2006). Moreover, people with more social connections in the neighbourhood tend to make more use of its services and facilities while also being more involved in local activities. (Mackenbach et al., 2016).

The third level refers to method and the fact that the assessment of social impacts is difficult and time consuming. For social impact assessment, there is a broad range of quantitative (models, trends projections, scenarios, comparison of case studies) and qualitative (participatory approaches) techniques with subjective and objective indicators (Arce-Gomez et al., 2015; Karami et al., 2017). While there are resources and tools to measure the social determinants of health, there is little consensus on the indicators used (Elias et al., 2019). Some studies have focused on measuring social cohesion or mainly one aspect such as networks, trust, civic engagement, collective action, coordination with institutions dimensions (Cabrera and Najarian, 2015; (Villalonga-Olives and Kawachi, 
2015). Measuring each dimension precisely with all the indicators would have required significant work and time, which is not compatible with an HIA, the timing of which must match that of the decision. SCo is one of several determinants that must also be assessed. The aim of HIA is to build a solid and credible argument based on a combination of scientific knowledge and field data in order to make the links between the project and health intelligible and lead to a review of the project. As with all intervention research, HIA needs to be useful. Moreover, the assessment of social cohesion has to be modest regarding the other factors that are not related to urban policies but to social policies and housing policies that are beyond the scope of HIA and out of control of urban planners. This issue raises the question of the scope of HIA and the rooms for manoeuvre in making the project evolve.

\section{Three levels of strengths}

Despite these limitations, this framework is a useful tool for HIA. First, as mentioned above, in both the HIA guides and reports on this issue, we did not find any guidelines for assessing social cohesion. Therefore, it constitutes a further step towards increased understanding of how to address social cohesion.

Second, instead of just looking for characteristics that have been commonly associated with more social interactions and better cohesion, this framework allows us to ask the question, "how could it work?" taking into consideration not only physical aspects, but also perceptions and human factors. Hence, it can be used in the field without relying on a checklist, but rather on an overall analysis of all these potential indicators. This helps to identify what configuration could work at a specific local level, according to context. This double approach also enables us to consider different scales and perspectives on SCo: 
people scale (what they see as their neighbourhood) and the project scale (a macro approach).

Finally, it opens the way for considering social issues more thoroughly with a specific focus on equity. Thanks to a variety of indicators, dimensions and criteria, it rebalances the HIA analysis between environmental and social aspects.

\section{CONCLUSION}

Due to the complexity of the concept of social cohesion, we proposed a specific framework to help practitioners assess it in HIA. The assessed interventions such as the components of an urban development project, are new "events in systems" (Shiell et al., 2018) because they modify the urban environment for a multitude of reasons including geographical characteristics, mobility or opportunities of encounters. Thus, the answer to the question of whether urban design interventions have potential impacts on SCo cannot be binary. It depends on the way the intervention is implemented, the characteristics of the populations and the interactions with related policies. HIA practitioners assessing SCo need to keep in mind the need for a holistic, dynamic and multidisciplinary perspective but also a flexible approach in order to tailor the framework to each unique situation. This framework should be tested further to improve its validity and increase the ability of HIA to explore the links between urban projects and health through social impacts. For the future, this framework could be adjusted for HIA in other policies areas. 
Arce-Gomez, A., Donovan, J.D., Bedggood, R.E., 2015. Social impact assessments: Developing a consolidated conceptual framework. Environmental Impact Assessment Review 50, 85-94. https://doi.org/10.1016/j.eiar.2014.08.006

Bacqué, M., Fijalkow, Y., Launay, L., Vermeersch, S., 2011. Social mix policies in Paris: discourses, policies and social effects. International Journal of Urban and Regional Research 35, 256-273.

Baldwin, C., 2015. Assessing impacts on people's relationships to place and community in health impact assessment: an anthropological approach. Impact Assessment and Project Appraisal 33, 154-159. https://doi.org/10.1080/14615517.2014.983725

Baum, F.E., Ziersch, A.M., Zhang, G., Osborne, K., 2009. Do perceived neighbourhood cohesion and safety contribute to neighbourhood differences in health? Health \& Place 15, 925-934. https://doi.org/10.1016/j.healthplace.2009.02.013

Beauregard, L., Dumont, S., 1996. La mesure du soutien social. ss 45, 55-76. https://doi.org/10.7202/706737ar

Berkman, L.F., Glass, T., Brissette, I., Seeman, T.E., 2000. From social integration to health: Durkheim in the new millennium ir. Social Science \& Medicine 51, 843-857. https://doi.org/10.1016/S0277-9536(00)00065-4

Boessen, A., Hipp, J.R., Butts, C.T., Nagle, N.N., Smith, E.J., 2017. The built environment, spatial scale, and social networks: Do land uses matter for personal network structure? Environment and Planning B: Urban Analytics and City Science 2399808317690158. https://doi.org/10.1177/2399808317690158

Bourdieu, P., 1980. Le capital social. Actes de la recherche en sciences sociales 31, 2-3.

Cabrera, J.F., Najarian, J.C., 2015. How the Built Environment Shapes Spatial Bridging Ties and Social Capital. Environment and Behavior 47, 239-267.

Carpiano, R.M., 2006. Toward a neighborhood resource-based theory of social capital for health: Can Bourdieu and sociology help? Social Science \& Medicine 62, 165-175. https://doi.org/10.1016/j.socscimed.2005.05.020

Chaix, B., Lindström, M., Rosvall, M., Merlo, J., 2008. Neighbourhood social interactions and risk of acute myocardial infarction. J Epidemiol Community Health 62, 62-68. https://doi.org/10.1136/jech.2006.056960

Cohen, D.A., Inagami, S., Finch, B., 2008. The built environment and collective efficacy. Health \& place 14, 198-208.

d'Hombres, B., Rocco, L., Suhrcke, M., McKee, M., 2010. Does social capital determine health? Evidence from eight transition countries. Health Econ. 19, 56-74. https://doi.org/10.1002/hec.1445

Dannenberg, A.L., 2016. Peer reviewed: Effectiveness of health impact assessments: A synthesis of data from five impact evaluation reports. Preventing chronic disease 13.

Delves-Yates, C., Stockl, A., Moore, J., 2018. Making sense of concept analysis. Nurse Researcher $(2014+)$ 25, 43.

Ehsan, A., Klaas, H.S., Bastianen, A., Spini, D., 2019. Social capital and health: A systematic review of systematic reviews. SSM - Population Health 8, 100425. https://doi.org/10.1016/j.ssmph.2019.100425

Ehsan, A.M., Silva, M.J.D., 2015. Social capital and common mental disorder: a systematic review. J Epidemiol Community Health 69, 1021-1028. https://doi.org/10.1136/jech-2015-205868

Elias, R.R., Jutte, D.P., Moore, A., 2019. Exploring consensus across sectors for measuring the social determinants of health. SSM - Population Health 7, 100395. https://doi.org/10.1016/j.ssmph.2019.100395

Ewing, R., Kreutzer, R., 2006. Understanding the relationship between public health and the built environment. The Leed-ND Core Committee.

Fonseca, X., Lukosch, S., Brazier, F., 2019. Social cohesion revisited: a new definition and how to characterize it. Innovation: The European Journal of Social Science Research 32, 231-253. https://doi.org/10.1080/13511610.2018.1497480

Foster, S., Giles-Corti, B., Knuiman, M., 2010. Neighbourhood design and fear of crime: A socialecological examination of the correlates of residents' fear in new suburban housing developments. Health \& Place 16, 1156-1165. https://doi.org/10.1016/j.healthplace.2010.07.007 
Goldberg, M., Melchior, M., Leclerc, A., Lert, F., 2002. Les déterminants sociaux de la santé : apports récents de l'épidémiologie sociale et des sciences sociales de la santé. Sciences sociales et santé 20, 75-128. https://doi.org/10.3406/sosan.2002.1570

Goodchild, B., Cole, I., 2001. Social balance and mixed neighbourhoods in Britain since 1979: A review of discourse and practice in social housing. Environment and Planning D: Society and Space 19, 103-121.

Granovetter, M.S., 1973. The Strength of Weak Ties. American Journal of Sociology 78, 1360-1380. https://doi.org/10.1086/225469

Green, L., Gray, B.J., Edmonds, N., Parry-Williams, L., 2019. Development of a quality assurance review framework for health impact assessments. Impact Assessment and Project Appraisal 37, 107-113. https://doi.org/10.1080/14615517.2018.1488535

Grootaert, C., Van Bastelaer, T., 2001. Understanding and measuring social capital: A synthesis of findings and recommendations from the social capital initiative. World Bank, Social Development Family, Environmentally and Socially ....

Guibet-Lafaye, C., Kieffer, A., 2012. Interprétations de la cohésion sociale et perceptions du rôle des institutions de l'État social. L'Année sociologique 62, 195-241.

Hamano, T., Li, X., Sundquist, J., Sundquist, K., 2019. Neighborhood linking social capital as a predictor of lung cancer: A Swedish national cohort study. Cancer Epidemiology 61, 23-29. https://doi.org/10.1016/j.canep.2019.05.005

Hanna, K.S., Dale, A., Ling, C., 2009. Social capital and quality of place: reflections on growth and change in a small town. Local Environment 14, 31-44.

Harris-Roxas, B., Viliani, F., Bond, A., Cave, B., Divall, M., Furu, P., Harris, P., Soeberg, M., Wernham, A., Winkler, M., 2012. Health impact assessment: the state of the art. Impact Assessment and Project Appraisal 30, 43-52. https://doi.org/10.1080/14615517.2012.666035

Hassen, N., Kaufman, P., 2016. Examining the role of urban street design in enhancing community engagement: A literature review. Health \& Place 41, 119-132. https://doi.org/10.1016/j.healthplace.2016.08.005

Hillier, B., 2004. Can streets be made safe? Urban design international 9, 31-45.

Hu, F., Hu, B., Chen, R., Ma, Y., Niu, L., Qin, X., Hu, Z., 2014. A systematic review of social capital and chronic non-communicable diseases. Biosci Trends 8, 290-296. https://doi.org/10.5582/bst.2014.01138

Jenkinson, C.E., Dickens, A.P., Jones, K., Thompson-Coon, J., Taylor, R.S., Rogers, M., Bambra, C.L., Lang, I., Richards, S.H., 2013. Is volunteering a public health intervention? A systematic review and meta-analysis of the health and survival of volunteers. BMC public health 13, 773.

Karami, S., Karami, E., Buys, L., Drogemuller, R., 2017. System dynamic simulation: A new method in social impact assessment (SIA). Environmental Impact Assessment Review 62, 25-34. https://doi.org/10.1016/j.eiar.2016.07.009

Kawachi, I., Kennedy, B.P., Glass, R., 1999. Social capital and self-rated health: a contextual analysis. Am J Public Health 89, 1187-1193. https://doi.org/10.2105/AJPH.89.8.1187

Kearns, A., Forrest, R., 2000. Social Cohesion and Multilevel Urban Governance. Urban Studies 37, 995-1017. https://doi.org/10.1080/00420980050011208

Kemm, J. (Ed.), 2012. Health Impact Assessment: Past Achievement, Current Understanding, and Future Progress. Oxford University Press.

Kempen, R. van, Bolt, G., 2009. Social cohesion, social mix, and urban policies in the Netherlands. J Hous and the Built Environ 24, 457. https://doi.org/10.1007/s10901-009-9161-1

Klein, C., 2013. Social Capital or Social Cohesion: What Matters For Subjective Well-Being? Social Indicators Research 110, 891-911. https://doi.org/10.1007/s11205-011-9963-x

Lavin, T., Higgins, C., Metcalfe, O., Jordan, A., 2006. Health Impacts of the Built Environment - A Review. Institute of Public Health in Ireland.

Lelévrier, C., 2013. Social mix neighbourhood policies and social interaction: The experience of newcomers in three new renewal developments in France. Cities 35, 409-416.

Leslie, E., Cerin, E., 2008. Are perceptions of the local environment related to neighbourhood satisfaction and mental health in adults? Preventive Medicine 47, 273-278. https://doi.org/10.1016/j.ypmed.2008.01.014

Liska, A.E., Sanchirico, A., Reed, M.D., 1988. Fear of crime and constrained behavior specifying and estimating a reciprocal effects model. Social Forces 827-837.

Maass, R., Kloeckner, C.A., Lindstrøm, B., Lillefjell, M., 2016. The impact of neighborhood social capital on life satisfaction and self-rated health: A possible pathway for health promotion? Health \& Place 42, 120-128. https://doi.org/10.1016/j.healthplace.2016.09.011 
Mackenbach, J.D., Lakerveld, J., van Lenthe, F.J., Bárdos, H., Glonti, K., Compernolle, S., De Bourdeaudhuij, I., Oppert, J.-M., Roda, C., Rutter, H., Brug, J., Nijpels, G., 2016. Exploring why residents of socioeconomically deprived neighbourhoods have less favourable perceptions of their neighbourhood environment than residents of wealthy neighbourhoods. Obesity Reviews 17, 42-52. https://doi.org/10.1111/obr.12375

Mazumdar, S., Learnihan, V., Cochrane, T., Davey, R., 2017. The Built Environment and Social Capital: A Systematic Review. Environment and Behavior 0013916516687343. https://doi.org/10.1177/0013916516687343

McPherson, K., Kerr, S., McGee, E., Cheater, F., Morgan, A., 2013. The Role and Impact of Social Capital on the Health and Wellbeing of Children and Adolescents: a systematic review. Glasgow Centre for Population Health, Glasgow Caledonian University.

Meijer, M., Röhl, J., Bloomfield, K., Grittner, U., 2012. Do neighborhoods affect individual mortality? A systematic review and meta-analysis of multilevel studies. Social Science \& Medicine 74, 1204-1212. https://doi.org/10.1016/j.socscimed.2011.11.034

Melis, G., Marra, G., Gelormino, E., 2013. Housing and Social Mix, Equity Action Work Package 6 Literature Review. Higher Institute on Territorial Systems for Innovation - SiTI.

Moore, S., Kawachi, I., 2017. Twenty years of social capital and health research: a glossary. J Epidemiol Community Health 71, 513-517. https://doi.org/10.1136/jech-2016-208313

Mpanje, D., Gibbons, P., McDermott, R., 2018. Social capital in vulnerable urban settings: an analytical framework. Journal of International Humanitarian Action 3, 4.

Mugnano, S., Palvarini, P., 2013. "Sharing space without hanging together": A case study of social mix policy in Milan. Cities 35, 417-422. https://doi.org/10.1016/j.cities.2013.03.008

Murayama, H., Fujiwara, Y., Kawachi, I., 2012. Social Capital and Health: A Review of Prospective Multilevel Studies. J Epidemiol 22, 179-187. https://doi.org/10.2188/jea.JE20110128

Nyqvist, F., Pape, B., Pellfolk, T., Forsman, A.K., Wahlbeck, K., 2014. Structural and Cognitive Aspects of Social Capital and All-Cause Mortality: A Meta-Analysis of Cohort Studies. Social Indicators Research 116, 545-566.

Ottoni, C.A., Sims-Gould, J., Winters, M., Heijnen, M., McKay, H.A., 2016. "Benches become like porches": Built and social environment influences on older adults' experiences of mobility and well-being. Social Science \& Medicine 169, 33-41. https://doi.org/10.1016/j.socscimed.2016.08.044

Phillips, D., 2006. Parallel lives? Challenging discourses of British Muslim self-segregation. Environment and Planning D: Society and Space 24, 25-40.

Portes, A., 1998. Social Capital: Its Origins and Applications in Modern Sociology. Annual Review of Sociology 24, 1-24. https://doi.org/10.1146/annurev.soc.24.1.1

Renalds, A., Smith, T.H., Hale, P.J., 2010. A systematic review of built environment and health. Fam Community Health 33, 68-78. https://doi.org/10.1097/FCH.0b013e3181c4e2e5

Rodgers, B.L., 1989. Concepts, analysis and the development of nursing knowledge: the evolutionary cycle. Journal of advanced nursing 14, 330-335.

Roof, K., Oleru, N., 2008. Public health: Seattle and King County's push for the built environment. Journal of environmental health 71, 24-27.

Shiell, A., Hawe, P., Kavanagh, S., 2018. Evidence suggests a need to rethink social capital and social capital interventions. Social Science \& Medicine 111930. https://doi.org/10.1016/j.socscimed.2018.09.006

Silver, H., 2007. Social exclusion: Comparative analysis of Europe and Middle East youth.

Stansfeld, S.A., 1999. Social support and social cohesion, in: Marmot, M., Wilkinson, R. (Eds.), Social Determinants of Health. Oxford, Oxford University Press., pp. 155-178.

Tomlins, R., Johnson, M.R., Owen, D., 2002. The resource of ethnicity in the housing careers and preferences of the Vietnamese communities in London. Housing Studies 17, 505-519.

Villalonga-Olives, E., Kawachi, I., 2017. The dark side of social capital: A systematic review of the negative health effects of social capital. Social Science \& Medicine 194, 105-127. https://doi.org/10.1016/j.socscimed.2017.10.020

Villalonga-Olives, E., Kawachi, I., 2015. The measurement of bridging social capital in population health research. Health \& Place 36, 47-56. https://doi.org/10.1016/j.healthplace.2015.09.002

Villalonga-Olives, E., Wind, T.R., Kawachi, I., 2018. Social capital interventions in public health: A systematic review. Social Science \& Medicine 212, 203-218. https://doi.org/10.1016/j.socscimed.2018.07.022 
Walsh, D., McCartney, G., McCullough, S., van der Pol, M., Buchanan, D., Jones, R., 2015. Comparing levels of social capital in three northern post-industrial UK cities. Public Health 129, 629-638. https://doi.org/10.1016/j.puhe.2015.02.024

Wood, L., Shannon, T., Bulsara, M., Pikora, T., McCormack, G., Giles-Corti, B., 2008. The anatomy of the safe and social suburb: An exploratory study of the built environment, social capital and residents' perceptions of safety. Health \& Place 14, 15-31. https://doi.org/10.1016/j.healthplace.2007.04.004

World Health Organization, 1999. Health impact assessment: main concepts and suggested approach, Gothenburg Consensus Paper, Bruxelles.

World Health Organization, 1986. Charte d'Ottawa. WHO.

Yuma-Guerrero, P.J., Cubbin, C., von Sternberg, K., 2017. Neighborhood Social Cohesion as a Mediator of Neighborhood Conditions on Mothers' Engagement in Physical Activity: Results From the Geographic Research on Wellbeing Study. Health Education \& Behavior 1090198116687537. https://doi.org/10.1177/1090198116687537 


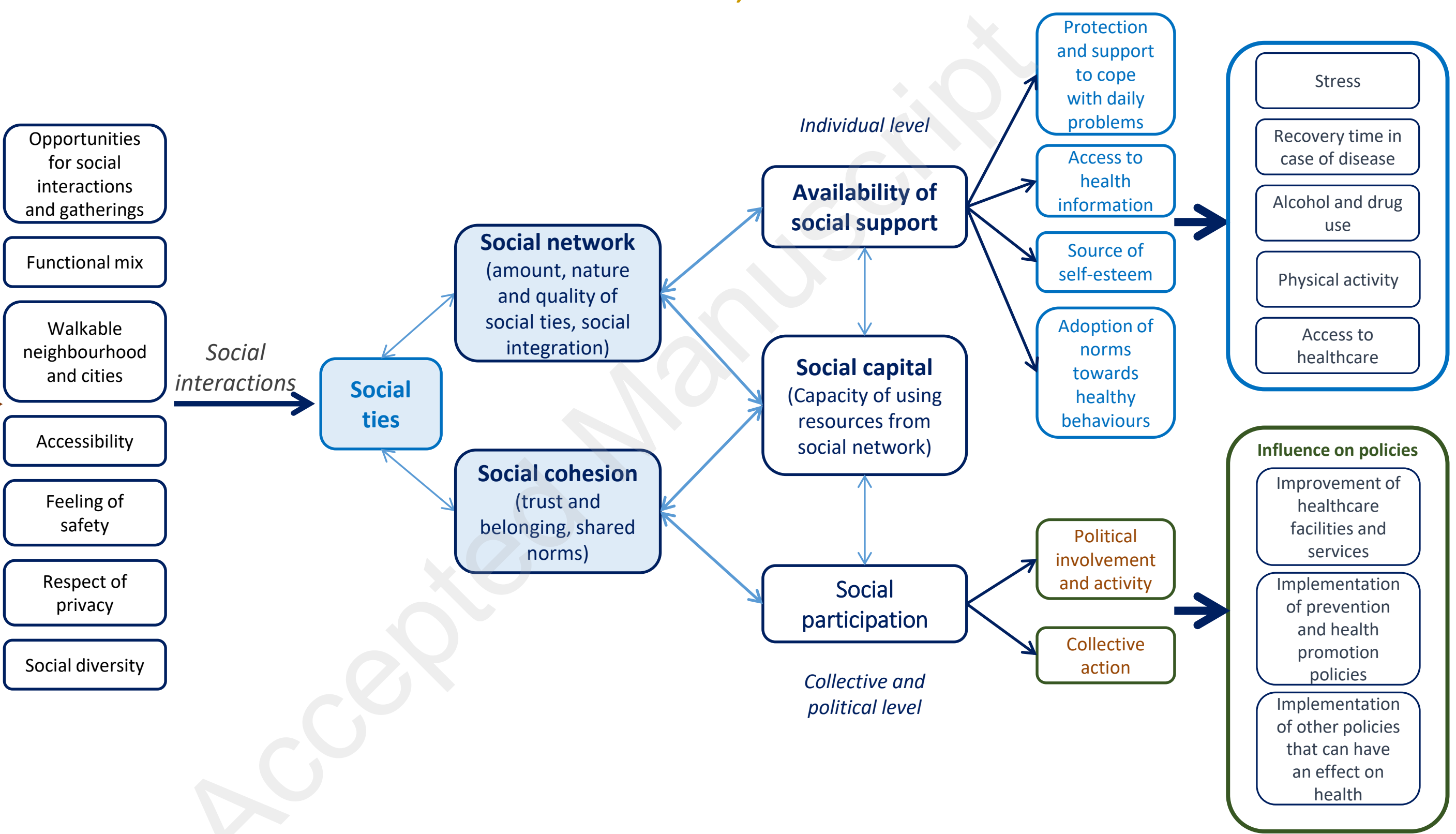


Social cohesion framework

\begin{tabular}{|c|c|c|c|}
\hline Urban project & Criteria & Questions & Variables \\
\hline \multirow{4}{*}{$\begin{array}{l}\text { Spatial aspect } \\
\text { Urban design }\end{array}$} & $\begin{array}{l}\text { Availability and } \\
\text { type of public } \\
\text { spaces }\end{array}$ & $\begin{array}{l}\text { Are there identifiable spaces that could foster social } \\
\text { interactions? }\end{array}$ & $\begin{array}{l}\text { - type of public space (place, square, parks, gardens street, sidewalks...) } \\
\text { - street furniture and facilities (benches, playground, etc.) } \\
\text { - potential users } \\
\text { - safety }\end{array}$ \\
\hline & $\begin{array}{l}\text { Accessibility } \\
\text { Walkability }\end{array}$ & $\begin{array}{l}\text { Are public spaces accessible? } \\
\text { Are public spaces connected to one another with accessible and } \\
\text { walkable paths? }\end{array}$ & $\begin{array}{l}\text { - distance (length, time) between spaces } \\
\text { - availability and safety of pedestrian and bike lanes } \\
\text { - presence of major barriers: crossroads, large roads with high level of } \\
\text { traffic } \\
\text { - quality of paths and spaces }\end{array}$ \\
\hline & $\begin{array}{l}\text { Quality of the } \\
\text { urban spaces }\end{array}$ & $\begin{array}{l}\text { Is the urban design considered as quality and aesthetically } \\
\text { pleasing? }\end{array}$ & $\begin{array}{l}\text { - design of green spaces and public space (colors, height of building, ...) } \\
\text { - preservation of the area's heritage }\end{array}$ \\
\hline & $\begin{array}{l}\text { Functional } \\
\text { diversity / mix }\end{array}$ & $\begin{array}{l}\text { How can facilities and services available in the neighborhood } \\
\text { foster social interactions? }\end{array}$ & $\begin{array}{l}\text { - available and accessible facilities (schools, sports facilities, cultural } \\
\text { facilities,... } \\
\text { - health and social services } \\
\text { - types of businesses } \\
\text { - collective community places (associations,...) }\end{array}$ \\
\hline \multirow[t]{2}{*}{$\begin{array}{l}\text { Human aspect } \\
\text { Actual and } \\
\text { future } \\
\text { population }\end{array}$} & Social diversity & $\begin{array}{l}\text { How does social mix contribute to creating links between } \\
\text { inhabitants and successfully promote people living together? On } \\
\text { what level? Between which groups? }\end{array}$ & $\begin{array}{l}\text { - type of diversity (social, cultural, generational) } \\
\text { - degree of proximity between social groups } \\
\text { - type of housing (residential houses, buildings with apartments, } \\
\text { number of apartments...) } \\
\text { - housing prices } \\
\text { - location of social housing in the neighborhood (center, fringe) } \\
\text { - scale of social diversity: within the same building, neighborhood } \\
\text { within schools, within sports facilities... }\end{array}$ \\
\hline & $\begin{array}{l}\text { Perceptions } \\
\text { (feeling of } \\
\text { safety, of } \\
\text { belonging) }\end{array}$ & $\begin{array}{l}\text { How do people perceive the neighborhood (safety, aesthetics, } \\
\text { cleanliness, peaceful, friendliness? } \\
\text { How do people perceive their neighbors \& other social groups? } \\
\text { Do they perceive or recognize the neighborhood as their own? }\end{array}$ & $\begin{array}{l}\text { - history of the neighborhood (evolution, special events...) } \\
\text { - perception of urban design } \\
\text { - perception of otherness } \\
\text { - attachment to the neighborhood } \\
\text { - sense of identity }\end{array}$ \\
\hline Social cohesion & & $\begin{array}{l}\text { How can the urban planning project contribute to social } \\
\text { cohesion within the neighborhood and with the } \\
\text { neighborhoods and surrounding? }\end{array}$ & $\begin{array}{l}\text { - shared needs, interests, values and expectations } \\
\text { - tolerance and acceptance of others } \\
\text { - shared identity \& feelings of belonging } \\
\text { - social distance }\end{array}$ \\
\hline
\end{tabular}

